Family Medicine and Community Health

\section{Effectiveness of an audit programme for dyslipidaemia management in a primary care setting in Macau: a quality improvement study}

In Wong, See Fai Tse, Chau Sha Kwok
To cite: Wong I, Tse SF, Kwok CS. Effectiveness of an audit programme for dyslipidaemia management in a primary care setting in Macau: a quality improvement study. Fam Med Com Health 2020;8:e000222. doi:10.1136/ fmch-2019-000222
Check for updates

(C) Author(s) (or their employer(s)) 2020. Re-use permitted under CC BY-NC. No commercial re-use. See rights and permissions. Published by BMJ.

Health Bureau, Macau SAR Government, Macau, China

Correspondence to Dr In Wong; michelle.wongin@gmail.com

\section{ABSTRACT}

Objective The objective of this study was to test the effectiveness of an audit programme for dyslipidaemia management in a primary care setting in Macau. Design A quality improvement study based on an evaluation of a before-after intervention trial was conducted in 2017-2018. Interventions comprising feedback from an audit, general practitioner (GP) training via interactive workshops and one-on-one case discussions were implemented. The primary outcome measure was the proportion of patients with reasonable management of dyslipidaemia, and the secondary outcome measure was the proportion of patients with lowdensity lipoprotein cholesterol (LDL-C) meeting the target recommended by the Adult Treatment Panel III guidelines. Setting This study was conducted at the Sao Lourenco Health Center, one of the health centres in the Macau primary care system; this centre provides primary care services to one-tenth of the residents of Macau.

Participants All GPs who worked in the Sao Lourenco Health Center participated in the study. We systematically reviewed 100 patient records from each participating physician's patient list. In total, 1200 and 1100 patient records were reviewed before and after the intervention, respectively.

Results At baseline, 390 (43.5\%) patients were eligible for statin therapy, while $411(47.7 \%)$ patients were eligible for statin therapy in the reaudit group $(p=0.08)$. After intervention, the proportion of patients with reasonable management of dyslipidaemia increased from $83.9 \%$ to $88.5 \%(p=0.005)$, and the proportion of eligible patients with LDL-C levels meeting the target increased from $55.1 \%$ to $65 \%$ ( $p=0.004)$.

Conclusions The audits and feedback significantly improved dyslipidaemia management in the Macau primary care setting.

\section{INTRODUCTION}

The Macau primary care system was established in the 1980s. After more than 30 years of development, it has become a comprehensive medical network. ${ }^{1}$

Dyslipidaemia is one of the major risk factors for cardiovascular disease (CVD), and statin therapy can effectively reduce the incidence of major coronary events and stroke. ${ }^{2-6}$ For every $1.0 \mathrm{mmol} / \mathrm{L}$ reduction in low-density lipoprotein cholesterol (LDL-C), the risk of coronary heart disease (CHD) mortality decreases by $19 \%$, and the risk of overall mortality decreases by $12 \%{ }^{7}$ In Macau, CVD is the second leading cause of death after malignancy. ${ }^{8}$ Therefore, good cholesterol control is an important factor in reducing the mortality rate and improving the health of Macau residents. At the same time, good cholesterol control also substantially reduces the government's financial expenditure on tertiary prevention.

More than $95 \%$ of Macau residents are Chinese. Other populations include native Portuguese and other ethnic minorities. Most patients with dyslipidaemia in Macau are followed up by general practitioners (GPs) in the primary care setting of the Macau Health Bureau. Most GPs in the Macau primary care setting prefer to manage dyslipidaemia based on the National Cholesterol Education Program Adult Treatment Panel (ATP) III guidelines. ${ }^{9}$ The strategy adopted by the ATP III guidelines is to first assess the patient's risk factors, then stratify the patient's risk level, and finally set the appropriate cholesterol control target based on the patient's risk level. For primary prevention, subjects assigned to statin therapy included those categorised as follows: (1) high risk (CHD risk equivalents or $\mathrm{CHD}$ risk factors $\geq 2$ and 10 -year risk for CHD $>20 \%$ ) with an LDL-C target of $<2.6 \mathrm{mmol} / \mathrm{L}$; (2) moderately high risk (CHD risk factors $\geq 2$ and 10 -year risk for CHD 10\%-20\%) with an LDL-C target of $<3.4 \mathrm{mmol} / \mathrm{L}$; (3) moderate risk (CHD risk factors $\geq 2$ and 10 -year risk for $\mathrm{CHD}<10 \%$ ) with an LDL-C target of $<3.4 \mathrm{mmol} / \mathrm{L}$ and (4) low risk (0-1 CHD risk factors) with an LDL-C target of $<4.2 \mathrm{mmol} / \mathrm{L}$. For secondary prevention, the LDL-C target should be lower than $2.6 \mathrm{mmol} / \mathrm{L} .{ }^{9}$ 
Based on the ATP III guidelines, the Framingham risk assessment ${ }^{10}$ was used to identify the patient's CHD risk. To this end, the Framingham risk assessment software was installed in the electronic medical record system of the Macau Health Bureau. Despite the simplicity and long-term effectiveness of dyslipidaemia interventions, the current quality of dyslipidaemia management in the Macau primary care setting is suboptimal, especially in high-risk patients. ${ }^{11}$

Combining audits with feedback is a method of improving the quality of healthcare; this method effectively improves patient management and health providers' adherence to treatment recommendations, as shown in previous observational studies. ${ }^{12-14}$ However, the Cochrane database systematic review in 2012 suggested that an audit and feedback programme led only to small although potentially important improvements in professional practice and that the effectiveness of an audit and feedback programme seems to depend on baseline performance and the manner in which feedback is provided. ${ }^{15}{ }^{16}$ Thus far, there are no similar studies or reports in Macau.

The objective of this study was to test the effectiveness of an audit programme to improve dyslipidaemia management among patients attending primary care clinics in Sao Lourenco Health Center by classifying their risk levels and measuring the proportions of patients who achieved reasonable management of dyslipidaemia and optimal cholesterol targets based on the ATP III guidelines. ${ }^{9}$

\section{METHODS}

\section{Context}

This quality improvement study was conducted at the Sao Lourenco Health Center, which is one of the health centres on the Macau Peninsula. As of 2017, the 52819 registered patients were equivalent to nearly one-tenth of the population of Macau and more than 95\% of them were Chinese. This study consisted of three steps: (1) baseline data collection (1 September 2017 to 31 December 2017); (2) feedback provided in an educational context (January 2018) and (3) secondary data collection to complete the audit cycle (1 September 2018 to 31 November 2018) (figure 1).

\section{Intervention}

The educational element consisted of a $120 \mathrm{~min}$ interactive workshop and a $15 \mathrm{~min}$ one-on-one discussion between the auditor and all GPs at the Sao Lourenco Health Center to discuss the steps involved in using the ATP III guidelines and ensure that all the participating GPs use the ATP III guidelines correctly. The workshop and one-on-one discussions were mainly based on the audit results. Additionally, all GPs received a personal audit report regarding dyslipidaemia management in their cases.

\section{Measures}

The baseline data collection was performed using computerised clinical records from 1 September 2017

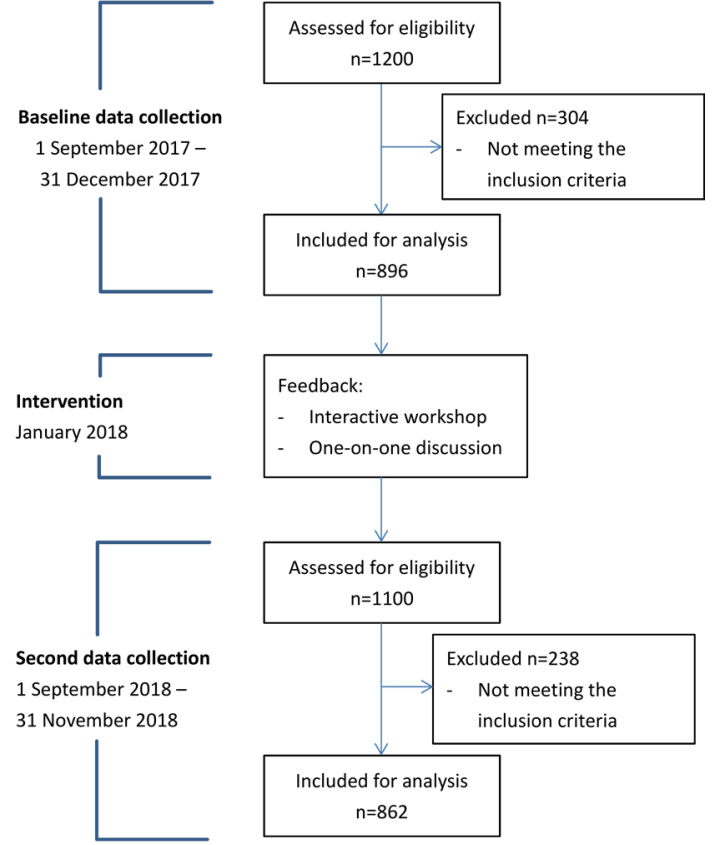

Figure 1 Study flow diagram.

to 31 December 2017. All 12 GPs who worked in the Sao Lourenco Health Center participated in the study. According to each GP's outpatient appointment list, we reviewed 100 consecutive patients according to when the patient came for follow-up. In total, 1200 patient records were systematically reviewed. The selected cases fulfilled all the following inclusion criteria: (1) patients aged $\geq 21$ and $\leq 75$ years, irrespective of sex; (2) patients who attended the Sao Lourenco Health Center primary care clinic at least once per year and who had a lipid profile record before the initiation of statin therapy and (3) patients with at least one lipid profile record within 3 years if the patient was not on a statin. The patients were excluded if they missed their appointment or did not fulfil the above inclusion criteria. Patient demographics, physical measures, lipid profiles, risk factors and concomitant medications were extracted from the computerised medical records. Ultimately, 896 patients fulfilled the inclusion criteria. The intervention was performed in January 2018. Approximately 9 months later, following the provision of feedback, a second data collection was performed with the computerised clinical records from 1 September 2018 to 31 November 2018, using the same method that was applied for the baseline data collection. In this step, all 11 GPs who currently worked in the Sao Lourenco Health Center participated, and 1100 records of patients who were seen by these 11 GPs were systematically reviewed. Ultimately, 862 patients fulfilled the inclusion criteria. It should be noted that the patients before the intervention and the patients after the intervention were not necessarily the same patients.

\section{Analysis}

Based on the ATP III guidelines, the patients' risk levels were based on their condition at the start of statin 
therapy, and the last lipid profile was used to evaluate the efficiency of statin therapy. ${ }^{9}$ The primary outcome was the proportions of patients with reasonable management (patients on statins who were eligible for statin therapy or patients not on statins who were not eligible), undertreatment (patients who were not on statins therapy but were eligible) and overtreatment (patients who were on statins even though they were not eligible). The secondary outcome was the proportion of patients with LDL-C levels meeting the target recommended by the ATP III guidelines. The proportions of patients achieving optimal cholesterol targets were compared between (1) before and after the intervention, (2) ATP III risk categories and (3) males and females.

The baseline data were collected from the cases of 12 GPs who worked in the Sao Lourenco Health Center. Two of the 12 GPs were transferred to another health centre, and one new physician started working at the Sao Lourenco Health Center in 2018. After the intervention, the reaudit data were collected from the 11 current GPs.

Categorical variables are expressed as proportions, while continuous variables are expressed as the mean \pm SD. Independent sample t-tests were used to compare normally distributed continuous variables, and Pearson's $\chi^{2}$ chisquare test was used to test for differences in the categorical variables. Where applicable, $\mathrm{p}<0.05$ was considered significant. Percentages were calculated on the basis of the total number of responses.

All statistical analyses were carried out using SPSS V.24 (IBM, Armonk, New York, USA).

\section{RESULTS}

\section{Overall patient cohort}

The general characteristics before and after the intervention are summarised in table 1 . There were no significant differences in the mean ages of the patients in the groups before and after the intervention. Compared with the patient group before the intervention, more patients with type 2 diabetes were included in the second data collection (21.5\% vs $27.8 \%, \mathrm{p}=0.002)$, and fewer patients were identified in the moderate-risk group $(1.2 \%$ vs $5 \% ; \mathrm{p}<0.0001)$ and the low-risk group $(57.6 \%$ vs $47.3 \%$; $\mathrm{p}<0.0001)$.

No significant differences were observed in the proportion of patients who were eligible for statins in the patient groups before and after the intervention $(43.5 \%$ vs $47.7 \%$; $=0.08$ ). Before the intervention, $83.9 \%$ of the patients were receiving reasonable management of dyslipidaemia; this percentage rose to $88.5 \%$, while fewer cases of overtreatment and undertreatment were observed at the second data collection $(\mathrm{p}=0.005)$ (table 2). Among the patients who were eligible for statins, LDL-C targets were achieved in $65 \%$ of the postintervention group and $55.1 \%$ of the preintervention group ( $\mathrm{p}=0.004)$ (table 3$)$.

In the patients who were eligible for statins, $80.7 \%$ were treated with simvastatin, $12 \%$ received atorvastatin and $7.3 \%$ received rosuvastatin at the second data collection. No significant difference was found with regard to the proportions in the preintervention patient group $(79.7 \%$, $12.5 \%$ and $7.8 \%$, respectively, $\mathrm{p}=0.943)$. Moreover, when comparing the mean dosage of statins between the preintervention and postintervention groups, no significant difference was observed between patients on simvastatin

Table 1 General characteristics of the overall cohort before and after intervention

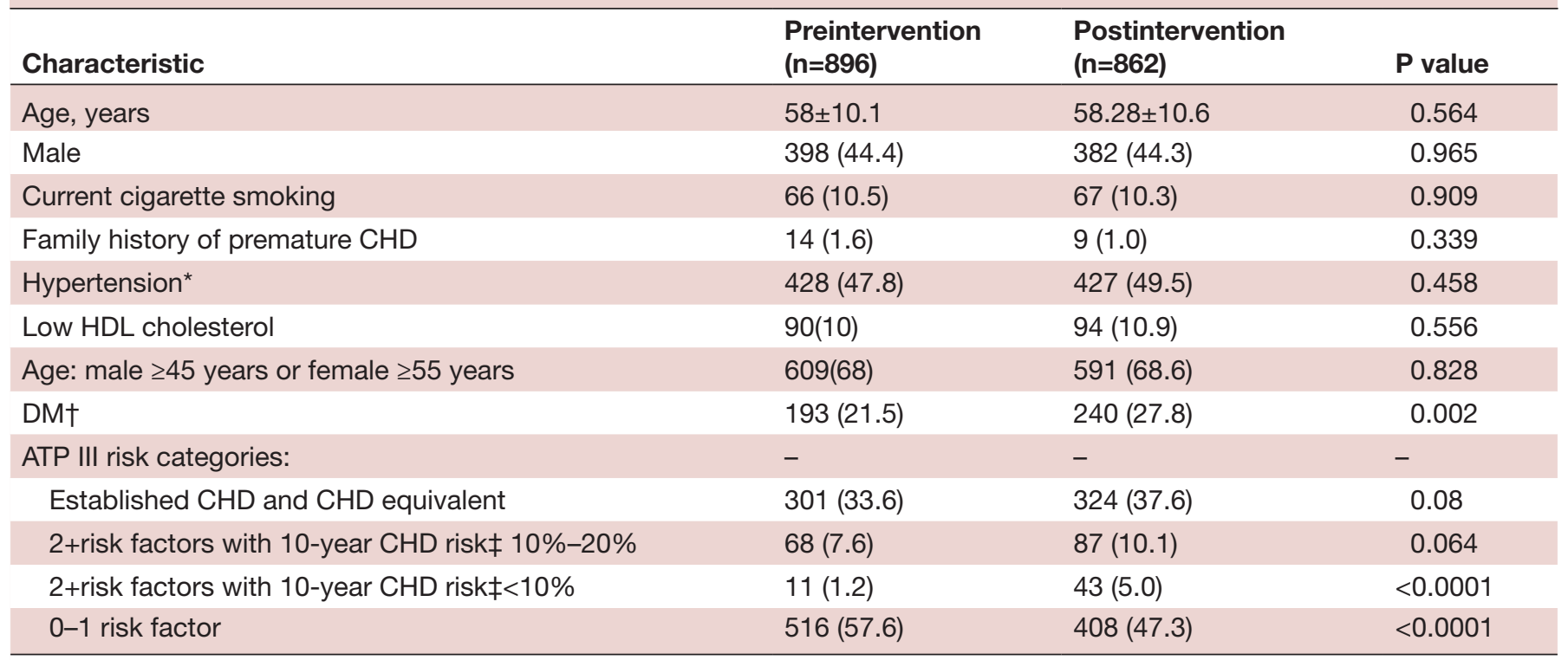

${ }^{*}$ On antihypertensive therapy or blood pressure $\geq 140 / 90 \mathrm{~mm} \mathrm{Hg}$.

†DM diagnosis according to ADA diagnostic criteria.

$\ddagger 10$-year CHD risk calculated by Framingham risk score.

ADA, American Diabetes Association; ATP, Adult Treatment Panel; CHD, coronary heart disease; DM, diabete mellitus; HDL, high-density lipoprotein. 
Table 2 Efficacy of dyslipidaemia management in the overall cohort before and after intervention

\begin{tabular}{llll}
\hline Characteristic & $\begin{array}{l}\text { Preintervention } \\
(\mathbf{n}=896)\end{array}$ & $\begin{array}{l}\text { Postintervention } \\
(\mathbf{n}=862)\end{array}$ & $\begin{array}{l}\mathbf{P} \\
\text { value }\end{array}$ \\
\hline $\begin{array}{l}\text { Eligible for statin } \\
\text { therapy }\end{array}$ & $390(43.5)$ & $411(47.7)$ & 0.08 \\
$\begin{array}{l}\text { Reasonable } \\
\text { management* }\end{array}$ & $752(83.9)$ & $763(88.5)$ & 0.005 \\
$\begin{array}{l}\text { Overtreatment } \\
\text { Undertreatment }\end{array}$ & $73(8.1)$ & $40(4.6)$ & 0.003 \\
\hline
\end{tabular}

${ }^{*}$ Reasonable management means patients on statins who were eligible for this therapy or patients not on statins who were not eligible.

(19.26 $\mathrm{mg}$ vs $20 \mathrm{mg}, \mathrm{p}=0.220)$ and atorvastatin (21.58 vs $23.54, p=0.385$ ), but a significantly higher dose of rosuvastatin was used in the postintervention group $(9.5 \mathrm{mg}$ vs $13.2 \mathrm{mg}, \mathrm{p}=0.009)$. In addition, compared with the patients who achieved the LDL-C target, those who did not achieve the LDL-C target were more likely to have hypertension (HTN) (63\% vs 69.7\%, p=0.048) and low high-density lipoprotein (HDL) levels $(12.7 \%$ vs $18.8 \%$, $\mathrm{p}=0.017)$ and to be smokers ( $13.9 \%$ vs $20.7 \%, \mathrm{p}=0.011)$.

\section{Lipid parameters}

Table 4 summarises the baseline lipid parameters of the groups before and after the intervention. There were no significant differences in the baseline LDL-C, HDL or triglyceride levels, but the patient group after intervention had a lower total cholesterol level $(\mathrm{p}=0.011)$.

\section{ATP III risk categories}

Based on the risk assessment using the ATP III guidelines, ${ }^{10}$ most patients were identified as being in the high-risk category (established CHD or 10 year CHD risk $>20$, diabetes mellitus) or the low-risk category (0-1 risk factor). Of the high-risk category patients, $20.3 \%$ were undertreated before the intervention, which decreased to $14.8 \%$ after the intervention, although the difference was not significant $(\mathrm{p}=0.073)$. Of the patients who were eligible for statins in this risk category, the proportion of patients achieving the LDL-C target was significantly higher in the postintervention group than in the preintervention group ( $61 \%$ vs $49.4 \%, p=0.007)$. Similar improvements in dyslipidaemia management were also seen in the lowrisk category patients. More patients received appropriate

\begin{tabular}{|c|c|c|c|}
\hline Characteristic & $\begin{array}{l}\text { Preintervention } \\
(n=390)\end{array}$ & $\begin{array}{l}\text { Postintervention } \\
(n=411)\end{array}$ & $P$ value \\
\hline $\begin{array}{l}\text { Statin use } \\
\text { appropriately } \\
\text { initiated }\end{array}$ & 319 (81.8) & 352 (85.6) & 0.14 \\
\hline Undertreatment & 71 (18.2) & $59(14.4)$ & 0.14 \\
\hline On target & 215 (55.1) & 267 (65.0) & 0.004 \\
\hline
\end{tabular}

Table 4 Cholesterol parameters in the overall cohort before and after intervention

\begin{tabular}{llll}
\hline $\begin{array}{l}\text { Baseline } \\
\text { parameter }\end{array}$ & $\begin{array}{l}\text { Preintervention } \\
(\mathbf{n}=896)\end{array}$ & $\begin{array}{l}\text { Postintervention } \\
(\mathbf{n}=862)\end{array}$ & $\begin{array}{l}\mathbf{P} \\
\text { value }\end{array}$ \\
\hline $\begin{array}{l}\text { Total cholesterol, } \\
\mathrm{mmol} / \mathrm{L}\end{array}$ & $5.69 \pm 2.53$ & $5.46 \pm 1.09$ & 0.011 \\
\hline $\mathrm{HDL}, \mathrm{mmol} / \mathrm{L}$ & $1.55 \pm 0.47$ & $1.53 \pm 0.61$ & 0.343 \\
\hline $\mathrm{LDL}, \mathrm{mmol} / \mathrm{L}$ & $3.37 \pm 1.06$ & $3.33 \pm 1.78$ & 0.625 \\
\hline $\mathrm{TG}, \mathrm{mmol} / \mathrm{L}$ & $1.67 \pm 1.95$ & $1.60 \pm 1.30$ & 0.370 \\
\hline
\end{tabular}

The above cholesterol parameters are before starting LDLlowering drugs or the last lipid profile if the patient was not on pharmacological therapy.

HDL, high-density lipoprotein; LDL, low-density lipoprotein; TG, triglycerides.

management of dyslipidaemia ( $86.2 \%$ vs $93.1 \%, \mathrm{p}=0.001)$ and less overtreatment $(12.6 \%$ vs $5.9 \%, \mathrm{p}=0.001)$, and more patients who were eligible for statins achieved the LDL-C target $(62.9 \%$ vs $80.9 \%, \mathrm{p}=0.014)$ (table 5$)$.

Table 5 Efficacy of dyslipidaemia management before and after intervention stratified by ATP III risk categories

\begin{tabular}{|c|c|c|c|}
\hline Characteristic & $\begin{array}{l}\text { Preintervention } \\
(\mathrm{n}=896)\end{array}$ & $\begin{array}{l}\text { Postintervention } \\
(n=862)\end{array}$ & $P$ value \\
\hline High-risk group & $(n=301)$ & $(n=324)$ & \\
\hline $\begin{array}{l}\text { Reasonable } \\
\text { management * }\end{array}$ & $234(77.7)$ & $268(82.7)$ & 0.118 \\
\hline Overtreatment & $6(2 \%)$ & $8(2.5)$ & 0.688 \\
\hline Undertreatment & $61(20.3)$ & $48(14.8)$ & 0.073 \\
\hline On target $†$ & 126 (49.4) & $175(61.0)$ & 0.007 \\
\hline $\begin{array}{l}\text { Moderately high- } \\
\text { risk group }\end{array}$ & $(n=68)$ & $(n=87)$ & \\
\hline $\begin{array}{l}\text { Reasonable } \\
\text { management * }\end{array}$ & $64(94.1)$ & $79(90.8)$ & 0.444 \\
\hline Overtreatment & $3(4.4)$ & $5(5.7)$ & 0.441 \\
\hline Undertreatment & $1(1.5)$ & $3(3.4)$ & 0.441 \\
\hline On target† & $29(70.7)$ & $31(70.5)$ & 0.978 \\
\hline $\begin{array}{l}\text { Moderate-risk } \\
\text { group }\end{array}$ & $(n=11)$ & $(n=43)$ & \\
\hline $\begin{array}{l}\text { Reasonable } \\
\text { management * }\end{array}$ & $9(81.8)$ & 36 (83.71) & 0.880 \\
\hline Overtreatment & $1(9.1)$ & $2(4.7)$ & 0.811 \\
\hline Undertreatment & $1(9.1)$ & 5 (11.6) & 0.566 \\
\hline On target $†$ & $4(80.01 \%)$ & $6(50)$ & 0.252 \\
\hline Low-risk group & $(n=516)$ & $(n=408)$ & \\
\hline $\begin{array}{l}\text { Reasonable } \\
\text { management * }\end{array}$ & $445(86.2)$ & $380(93.1)$ & 0.001 \\
\hline Overtreatment & 65 (12.6) & $24(5.9)$ & 0.001 \\
\hline Undertreatment & $6(1)$ & $4(1)$ & 0.790 \\
\hline On target $†$ & 56 (62.9) & 55 (80.9) & 0.014 \\
\hline
\end{tabular}

${ }^{*}$ Reasonable management means patients on statins who were eligible for this therapy or patients not on statins who were not eligible. †On target means the LDL-C met the ATP III treatment target; it was calculated in the patients who were eligible for statins.

ATP, Adult Treatment Panel; LDL, low-density lipoprotein. 
Table 6 Efficacy of dyslipidaemia management before and after intervention stratified by sex

\begin{tabular}{|c|c|c|c|}
\hline Characteristic & $\begin{array}{l}\text { Preintervention } \\
(n=896)\end{array}$ & $\begin{array}{l}\text { Postintervention } \\
(n=862)\end{array}$ & $P$ value \\
\hline Male & $(n=398)$ & $(n=382)$ & \\
\hline $\begin{array}{l}\text { Eligible for } \\
\text { statins }\end{array}$ & $211(53)$ & 229 (59.9) & 0.051 \\
\hline $\begin{array}{l}\text { Reasonable } \\
\text { management }^{\star}\end{array}$ & $333(83.7)$ & $324(84.8)$ & 0.660 \\
\hline Overtreatment & $22(5.5)$ & $17(4.5)$ & 0.49 \\
\hline Undertreatment & $43(10.8)$ & $41(10.7)$ & 0.974 \\
\hline Female & $(n=498)$ & $(n=480)$ & \\
\hline Eligible for statins & $179(35.9)$ & $182(37.9)$ & 0.523 \\
\hline $\begin{array}{l}\text { Reasonable } \\
\text { management }^{\star}\end{array}$ & $419(84.1)$ & 439 (91.5) & $<0.0001$ \\
\hline Overtreatment & $51(10.2)$ & $23(4.8)$ & 0.001 \\
\hline Undertreatment & $28(5.6)$ & $18(3.8)$ & 0.167 \\
\hline $\begin{array}{l}\text { Males eligible for } \\
\text { statins }\end{array}$ & $(n=211)$ & $(n=229)$ & \\
\hline On statins & $168(79.6)$ & $188(82.1)$ & 0.509 \\
\hline On target & $108(51.2)$ & $144(62.9)$ & 0.013 \\
\hline $\begin{array}{l}\text { Females eligible } \\
\text { for statins }\end{array}$ & $(n=179)$ & $(n=182)$ & \\
\hline On statins & $151(84.4)$ & $164(90.1)$ & 0.101 \\
\hline On target & $107(59.8)$ & $123(67.6)$ & 0.123 \\
\hline
\end{tabular}

${ }^{*}$ Reasonable management means patients on statins who were eligible for this therapy or patients not on statins who were not eligible.

\section{Sex differences}

No significant difference in sex distribution was found between the groups before and after the intervention (table 1). Comparisons between sexes are shown in table 6 . Compared with men, women had a significant decrease in the overtreatment of dyslipidaemia after the intervention $(10.2 \%$ vs $4.8 \%$; $\mathrm{p}=0.001)$. Among the patients who were eligible for statins, male patients showed a significant increase in meeting LDL-C treatment targets after the intervention $(52.1 \%$ vs $62.9 \%$; $\mathrm{p}=0.013)$.

\section{DISCUSSION}

\section{Main findings}

The results of this study demonstrated that there was significant improvement in the proportion of patients achieving their LDL-C target following the audit and feedback intervention. The audit and feedback intervention focused on the identification of and setting of treatment targets for patients with dyslipidaemia, as recommended in the ATP III guidelines. ${ }^{10}$ One-on-one discussions between the auditor and GPs were used to identify the knowledge gaps each GP had regarding dyslipidaemia management based on the baseline data analysis. The intervention required some personnel time: approximately 2 hours was needed to review one physician's case records, a $120 \mathrm{~min}$ interactive workshop was conducted by one instructor and a 15 min one-on-one discussion was performed with each GP.

Failure to achieve LDL-C targets is prevalent worldwide. ${ }^{17-19}$ In the Dyslipidemia International Study, $44.5 \%$ of all patients from the Middle East achieved the LDL-C target, while only $30.5 \%$ of the very high-risk patients achieved their LDL-C target. ${ }^{17}$ In the UK, $63 \%$ of all patients achieved their LDL-C targets. ${ }^{18}$ In the European Study on Cardiovascular Risk Prevention and Management in Daily Practice (EURIKA), only $42 \%$ of all patients achieved their LDL-C targets. ${ }^{19}$ The audit programme in this study improved dyslipidaemia management and led to levels of target achievement similar to those in other developed countries.

Several reasons may explain the suboptimal control of dyslipidaemia in the Sao Lourenco Health Center. First, some GPs lacked awareness of the treatment guidelines, and knowledge gaps existed. Compared with the patients who achieved the LDL-C target, significantly more patients who did not achieve the LDL-C target had HTN and low HDL levels and were smokers, and these major risk factors for CHD were easily ignored by GPs when identifying the patients' risk categories. These results indicated that the CHD risk of some patients was underestimated and that their LDL-C targets were not sufficiently stringent. Additionally, some GPs use a fixed threshold to decide whether to start cholesterol therapy, leading to overtreatment of female patients. Second, there are many published guidelines for the management of dyslipidaemia in the world, but there is no clear recommendation from the Macau Health Bureau for primary care GPs to follow. The impact of conflicting guidelines will potentially create even more difficulty for GPs with regard to the appropriate identification of risk categories for their patients, leading to significant barriers to translating evidence-based, guidelinerecommended targets into routine primary practice. These barriers may include suboptimal drug or dose selection and failure to titrate therapy. Third, high staff turnover and chronic understaffing may also influence the management of dyslipidaemia. Finally, patient factors include inadequate attention to dyslipidaemia management and poor drug compliance.

After the intervention programme in this study, the GPs' knowledge of suboptimal management of dyslipidaemia was improved, and the participating GPs were clearly better able to identify a patient's risk category and set an ideal LDL-C target. With this improvement, more high-risk patients and male patients achieved their LDL-C targets, and more female patients received reasonable management of dyslipidaemia because they were classified in the correct risk category and treated with an optimal dosage of statin, enabling them to meet their LDL-C targets. The result of this study agrees with the conclusion of a systematic Cochrane review of audit and feedback programmes in 2009, which noted that the effectiveness of audit and feedback interventions is improved when feedback is delivered with specific suggestions for improvement. ${ }^{15}$ 


\section{Key points}

\section{Question: What is this research focused on exploring,} validating or solving?

- This study tested the effectiveness of an audit and feedback programme for dyslipidaemia management in a primary care setting in Macau.

\section{Finding: What conclusions did this research draw through design, method and analysis? \\ - The audits and feedback significantly improved dyslipidaemia man- agement in the Macau primary care setting.}

\section{Meaning: What is the value, meaning and impact of your research? Is there any follow-up study based on this research? \\ - The findings in this study support the use of audit and feedback pro- grammes in other primary care settings for improving dyslipidaemia management.}

\section{Strengths and limitations of the study}

Our study has several limitations that should be addressed. First, the risk estimation and lipid parameters were based on current or retrospective data rather than prospective observations; however, this study reflects the 'real-world' practice. Second, we cannot confirm that the GPs in the Sao Lourenco Health Center are representative of all GPs in the Macau primary care setting. The impact of selection bias is also unclear, given that non-participating GPs and their patients may have been less or more likely to follow the treatment guidelines and attain their targets.

\section{CONCLUSION}

The audit programme improved dyslipidaemia management in the primary care setting. As statin therapy can effectively reduce the incidence rates of major coronary events and stroke, clear guidelines for dyslipidaemia management should be developed, disseminated and implemented in the Macau primary care setting. GPs need to be adequately trained to ensure that patients receive appropriate treatment. At the same time, regular and individualised quality assessments of GPs can help improve the quality of their clinical work.

Acknowledgements The authors acknowledge the support of the director of Sao Lourenco Health Center and the GPs who participated in their research.

Contributors IW designed and conducted the study, including data collection, analysis and interpretation. IW also prepared the manuscript draft. SFT and CSK revised of the article critically. All authors approved the final version of manuscript.

Funding The authors have not declared a specific grant for this research from any funding agency in the public, commercial or not-for-profit sectors.

Competing interests None declared.

Patient consent for publication Not required.

Ethics approval The patients' identities were protected, and no individual patients could be identified from the data. The GPs participating in the study are all employees of the Macau Health Bureau; therefore, informed consent was not required. Ethical approval for the study was obtained from the Medical Ethical Committee of Centro Hospitalar Conde de Sao Januario (0219/SCSD/N/2018). The patients and doctors involved were not at risk of harm because this study was only an audit of patients with dyslipidaemia.

Provenance and peer review Not commissioned; externally peer reviewed.

Data availability statement Data are not publicly available but are available from Macau Health Bureau and the application must be submitted in writing to the Director of the Macau Health Bureau.

Open access This is an open access article distributed in accordance with the Creative Commons Attribution Non Commercial (CC BY-NC 4.0) license, which permits others to distribute, remix, adapt, build upon this work non-commercially, and license their derivative works on different terms, provided the original work is properly cited, appropriate credit is given, any changes made indicated, and the use is non-commercial. See: http://creativecommons.org/licenses/by-nc/4.0/.

\section{REFERENCES}

1 Breve história de desenvolvimento DOS Serviços de Saúde. Available: https://www. ssm. gov. mo/ Portal/ portal. aspx? lang= pt

2 Taylor F, Huffman MD, Macedo AF, et al. Statins for the primary prevention of cardiovascular disease. Cochrane Database Syst Rev 2013:CD004816.

3 Chou R, Dana T, Blazina I, et al. Statins for prevention of cardiovascular disease in adults: evidence report and systematic review for the US preventive services Task force. JAMA 2016;316:2008-24.

4 Nayak A, Hayen A, Zhu L, et al. Legacy effects of statins on cardiovascular and all-cause mortality: a meta-analysis. BMJ Open 2018;8:e020584.

5 Wang W, Zhang B, Wen W. Statins for the prevention of stroke: a meta-analysis of randomized controlled trials. PLoS One 2014;9:e92388.

6 Baigent C, Keech A, Kearney PM, et al. Efficacy and safety of cholesterol-lowering treatment: prospective meta-analysis of data from 90,056 participants in 14 randomised trials of statins. Lancet 2005;366:1267-78

7 Kearney PM, Blackwell L, Collins R, et al. Efficacy of cholesterollowering therapy in 18,686 people with diabetes in 14 randomised trials of statins: a meta-analysis. Lancet 2008;371:117-25.

8 de Saúde S, da Região G. Administrativa especial de Macau. Boletim estatístico [Internet], 2016. Available: www.ssm.gov.mo/statistic/ 2016/index.html

9 National Cholesterol Education Program (NCEP) Expert Panel on Detection, Evaluation, and Treatment of High Blood Cholesterol in Adults (Adult Treatment Panel III). Third report of the National cholesterol education program (NCEP) expert panel on detection, evaluation, and treatment of high blood cholesterol in adults (adult treatment panel III) final report. Circulation 2002;106:3143-421.

10 D'Agostino RB, Vasan RS, Pencina MJ, et al. General cardiovascular risk profile for use in primary care: the Framingham heart study. Circulation 2008;117:743-53.

11 In W. A pilot study of cholesterol management among patients in a Macau primary care setting. J Prim Care Gen Pract 2018;1:7-11.

12 Grilli R, Lomas J. Evaluating the message: the relationship between compliance rate and the subject of a practice guideline. Med Care 1994;32:202-13.

13 Burgers JS, Grol RPTM, Zaat JOM, et al. Characteristics of effective clinical guidelines for general practice. Br J Gen Pract 2003;53:15-19.

14 Foy R, MacLennan G, Grimshaw J, et al. Attributes of clinical recommendations that influence change in practice following audit and feedback. J Clin Epidemiol 2002;55:717-22.

15 Hysong SJ. Meta-Analysis: audit and feedback features impact effectiveness on care quality. Med Care 2009;47:356-63.

16 Ivers N, Jamtvedt G, Flottorp S, et al. Audit and feedback: effects on professional practice and healthcare outcomes. Cochrane Database Syst Rev 2012;6:CD000259.

17 Al Sifri SN, Almahmeed W, Azar S, et al. Results of the Dyslipidemia International Study (DYSIS)-Middle East: clinical perspective on the prevalence and characteristics of lipid abnormalities in the setting of chronic statin treatment. PLoS One 2014;9:e84350.

18 Vian A, Kotseva K, Turner EL, et al. Dyslipidaemia and atherosclerotic vascular disease: DYSIS results in the UK. $\mathrm{Br} J$ Cardiol 2013;20:S9-10.

19 Banegas JR, López-García E, Dallongeville J, et al. Achievement of treatment goals for primary prevention of cardiovascular disease in clinical practice across Europe: the EURIKA study. Eur Heart J 2011;32:2143-52. 